\title{
Odontogenic tumour of lip
}

\author{
F. M. COLE AND A. W. JONES
}

From the Department of Pathology, University of Manchester

SYNOPSIS There have been nine cases of 'calcifying epithelial odontogenic tumour' described so far. The histological pattern is quite distinctive, and one feature is the presence of abundant intracytoplasmic and stromal material which (Vickers, Dahlin, and Gorlin, 1965) has been shown to react histochemically as amyloid. The tumour is generally believed to be epithelial in origin, arising from the reduced enamel organ of an unerupted tooth with which all the tumours so far recorded are associated.

Another case is described, this time arising in the soft tissue of the lip and remote from a tooth. This tumour showed features which suggest that it is of odontoblastic origin and therefore not epithelial. Evidence is also produced to show that the 'amyloid-like' material is not degenerative but probably dentine being actively produced by the tumour cells themselves.

\section{CASE REPORT}

A 62-year-old man complained of a mass in the lip, which had been there for $\mathbf{3 0}$ years but had shown a slight increase in size in the last few months. It was not painful. The mass, $2 \mathrm{~cm}$. in its greatest diameter, was situated in the upper lip in the mid line between the mucocutaneous junction and the frenulum. When removed, it shelled out with no difficulty. A radiograph of this region taken after excision showed no sign of an unerupted tooth or other abnormality.

Macroscopically the specimen consisted of a wellencapsulated nodule $2 \times 1.8 \times 1.5 \mathrm{~cm}$. On section it showed a uniform grey-white surface with a delicate fibrous capsule.

MICROSCOPY The nodule consists of sheets of closelypacked cells with occasional whorl formation. The mass of cells is broken up by abundant pale pink-staining acellular stroma, many areas of which consist of irregularly shaped pools of homogeneous material (Fig. 1). In other areas the material shows a definite tubular structure, highly suggestive of dentine, with a central lumen surrounded by radiating fibrils (Fig. 2). These fibrils are about $1 \mu$ in diameter and in places are seen to be cytoplasmic extensions of those tumour cells immediately surrounding the tubular structures (Fig. 3). Other structures are seen in longitudinal section (Fig. 4).

The tumour cell is polyhedral with distinct cell outlines. The nucleus is usually centrally placed, but is often displaced to one side by homogeneous eosinophilic material similiar to that found in the stroma. Under these circumstances the cells bear a striking superficial resemblance to plasma cells (Fig. 5). The nuclei are vesicular with some variation in size and occasional

Received for publication 28 February 1967. giant forms. Mitoses are not seen. No intracytoplasmic calcification is present, though small foci are present in the stroma. No intercellular bridges or ameloblast-like cells are present. The eosinophilic material found within the cytoplasm, in the tubular structures, and in the homogeneous areas shows metachromasia with methyl violet and a strong affinity for Congo red. When stained with Congo red the material shows positive birefringence and dichroism. Unstained sections show a strong autofluorescence (Fig. 6) which is enhanced after staining by thioflavine $T$.

\section{DISCUSSION}

In 1958 Pindborg described three cases of 'calcifying epithelial odontogenic tumour'. This is an extremely rare tumour, four cases of which had been described before 1958, diagnosed variously as adenoid adamantoblastoma (Thoma and Goldman, 1946), ameloblastoma of unusual type with calcification (Ivy, 1948), malignant odontoma (Wunderer, 1953), and cystic complex odontoma (Stoopack, 1957). Since 1958 a further two cases have been recorded (Chaudhry, Holte, and Vickers, 1962; Lucas, 1964). Despite its distinctive histological appearance the tumour has not been described as arising in soft tissue or unassociated with an unerupted tooth. Because of this constant relationship with an embedded tooth, Pindborg felt that the tumour was odontogenic and that it was epithelial, arising from the reduced enamel organ of the associated tooth. Pindborg and subsequent writers regarded the stromal and intracellular calcifying eosinophilic material as a form of degeneration, and indeed 


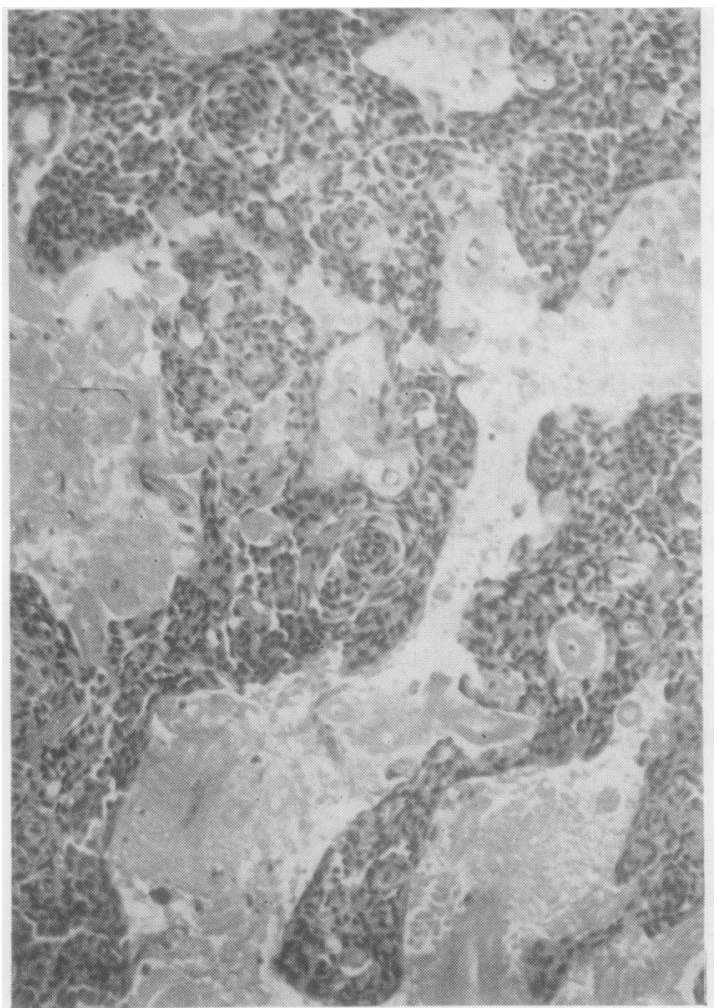

FIG. 1.

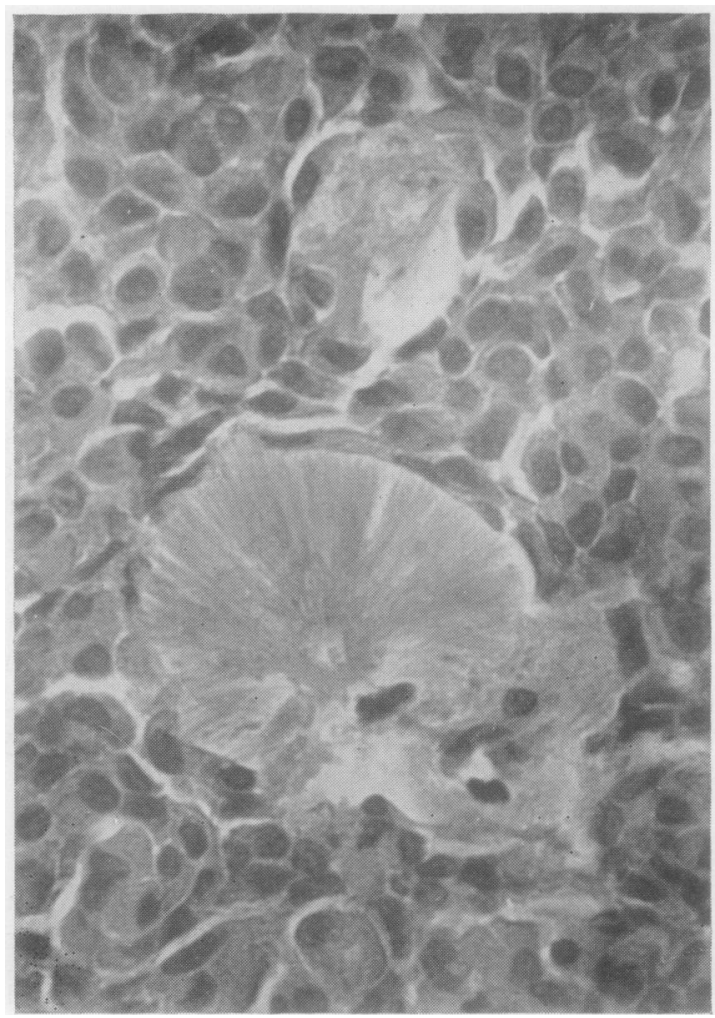

FIG. 2.

FIG. 1. The abundant stroma and occasional 'whorl' arrangement of tumour cells (haematoxylin and eosin $\times 50$ ).

FIG. 2. Dentine-like structure showing central lumen towards which the fibrils radiate (haematoxylin and eosin $\times 250$ ).

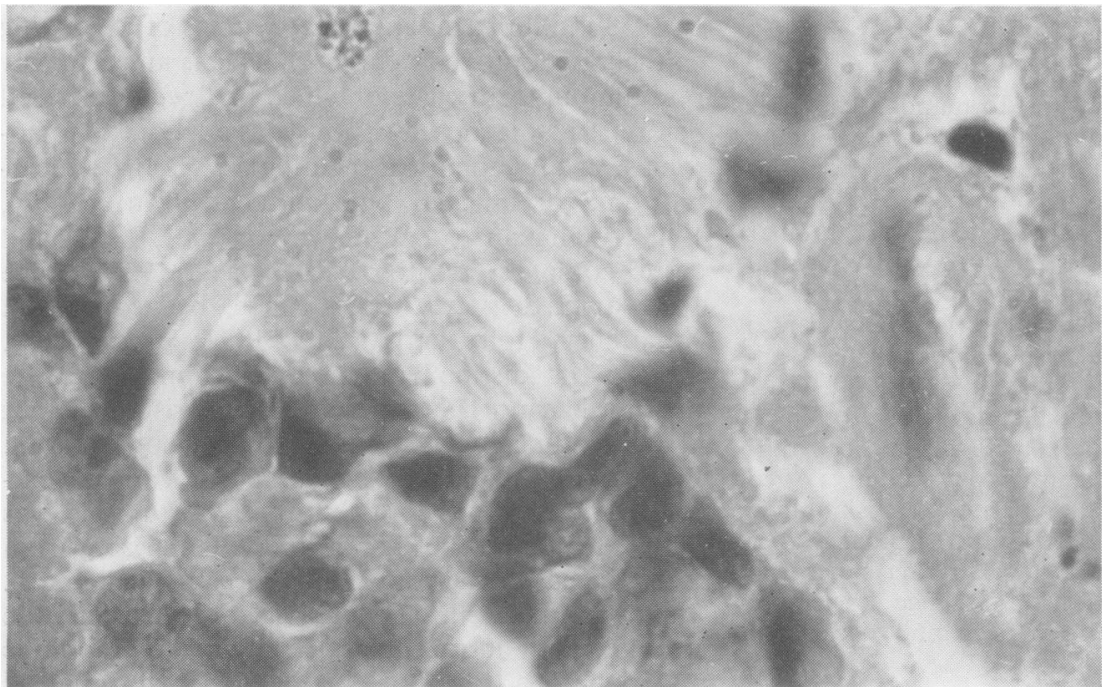

FIG. 3. Higher magnification showing fibrils arising from the cytoplasm of the cells bordering the tubular structures (haematoxylin and eosin $\times 450$ ). 


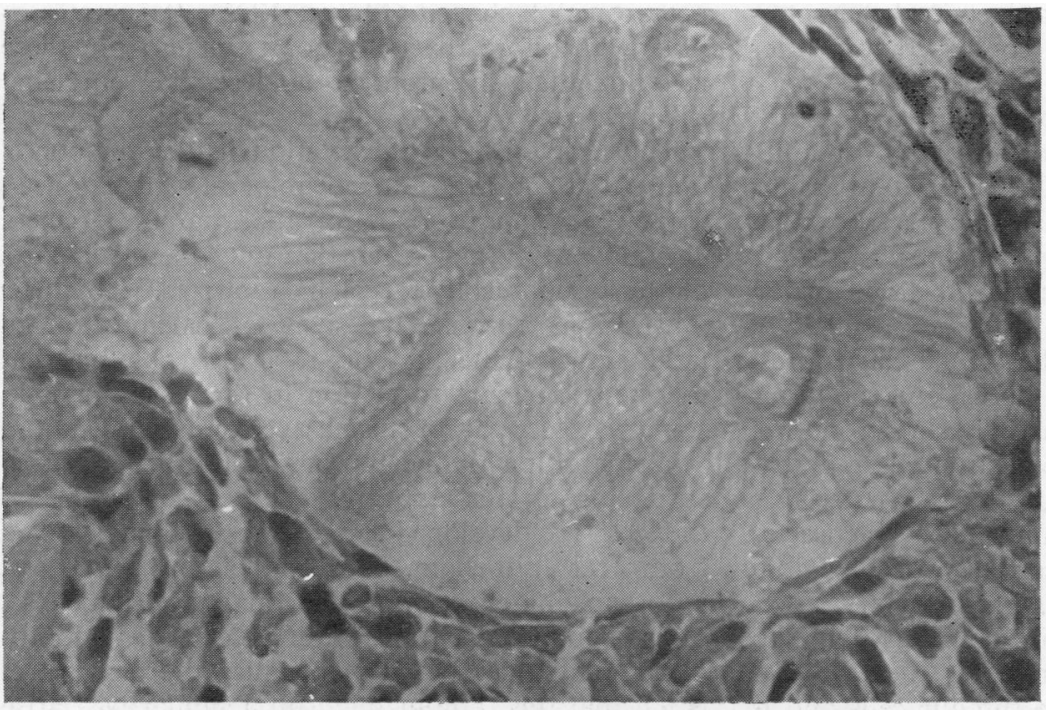

FIG. 4. A similar structure cut longitudinally (haematoxylin and eosin $\times 250$ ).

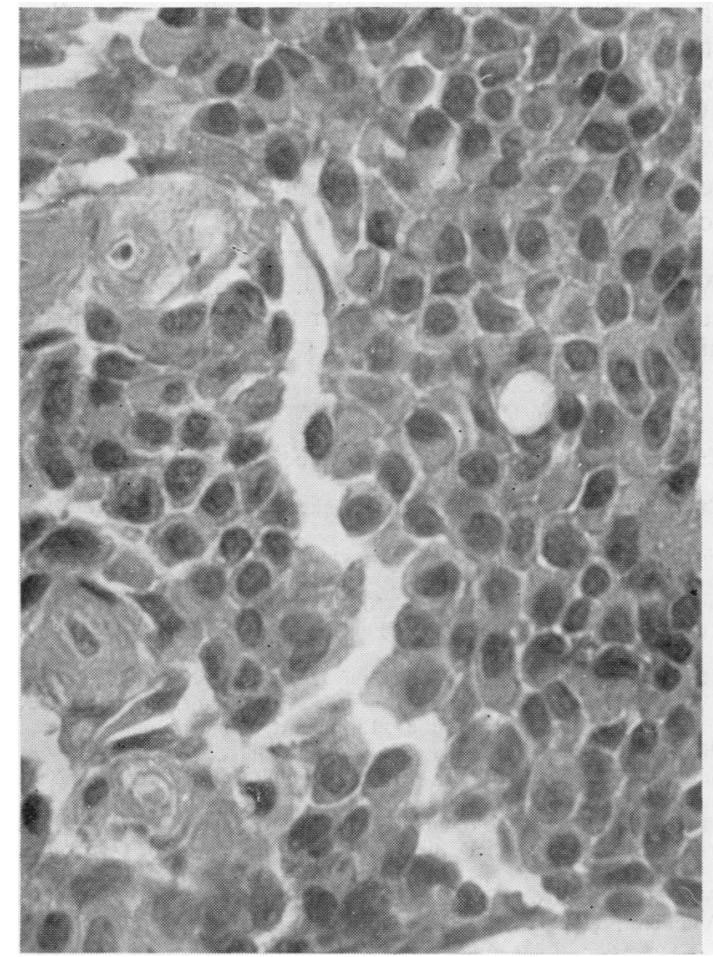

FIG. 5 .

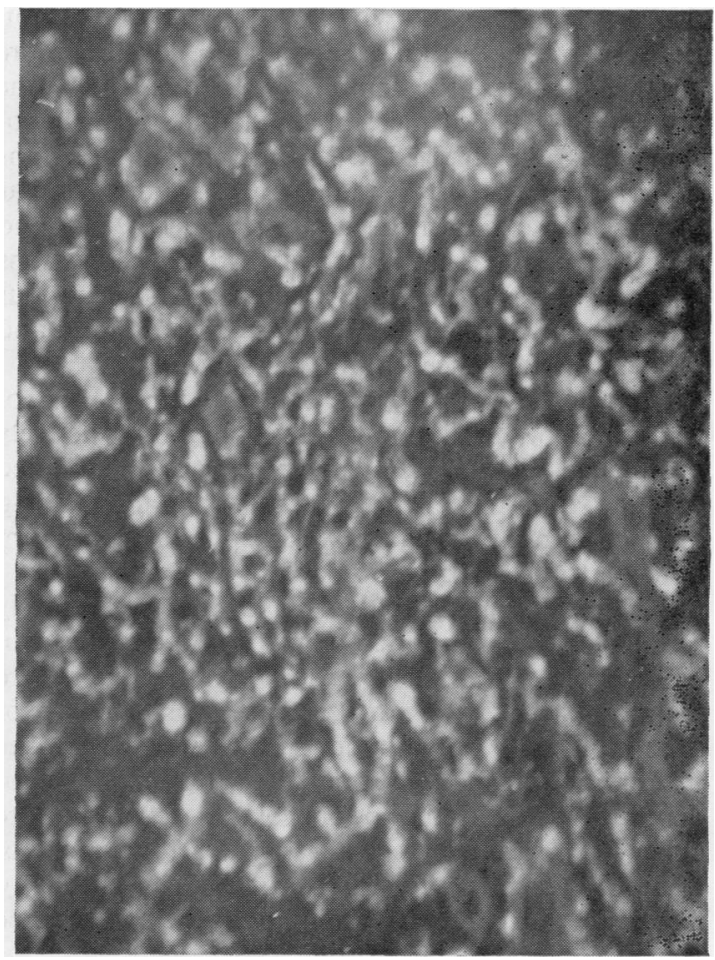

FIG. 6.

FIG. 5. Details of the tumour cells, some of which show the nucleus pushed to one side by cytoplasmic material similar to that found in the stroma. Note the resemblance of these cells to plasma cells (haematoxylin and eosin $\times 250$ ).

FIG. 6. Tumour cells showing autofluorescence of cytoplasmic material (ultra-violet light $\times 200$ ). 
Vickers et al. (1965) showed that it stained characteristically as amyloid. We have confirmed this latter finding.

It is also interesting to note that in the case of Chaudhry et al. (1962) the authors described 'dentinelike' structures in the stroma. The microphotographs of these lesions are very similar to those shown in Figure 2. These workers, however, did not express an opinion as to the significance and origin of the bodies.

There is little doubt that the tubular structures, the homogeneous eosinophilic pools, and the intracytoplasmic material are of basically similar nature, differing only in site and degree of structural differentiation. Furthermore it is clear that the material is being produced by the tumour cells themselves (Fig. 3). This substance is certainly not amyloid despite its staining properties. The fibrillary structure of the tubular bodies bears no resemblance to the appearance of classical amyloid; the fact that it occurs so abundantly in the tumour cells and is being produced by them substantiates this view. Furthermore the material fluoresces brightly in the unstained state, whereas amyloid does not. Because of the striking resemblance of the more organized areas to dentine, we investigated the possibility that dentine and pre-dentine react histochemically like amyloid. Decalcified paraffin sections of normal teeth were stained in a manner similar to that employed on the tumour, and it was found that the dentine gave identical staining reactions as the substance being produced by the tumour cells. It was also noted that unstained dentine and pre-dentine fluoresced in ultra-violet light.

On this basis we regard this tumour as one of well-differentiated odontoblasts which are actively producing dentine. Odontoblasts are modified connective tissue cells derived from the dental pulp and hence the view that this is an epithelial neoplasm appears to be no longer tenable.

The histological pattern, however, certainly resembles that of an epithelial tumour. This can be explained by consideration of the appearance of odontoblasts in a normal tooth. A single row of odontoblasts is only found during the early stages of dentinogenesis, but soon after the first layer of dentine thickens, the odontoblasts become more closely aggregated and a stratified formation of these cells takes place. The odontoblasts gradually lose their original high columnar outline and become pear- or club-shaped (Meyer, 1935). It is not surprising therefore that a tumour arising from these cells might also produce a deceptive epithelial appearance.

The lack of gross calcification in the tumour is unusual as the deposition of mineral salts has been considered characteristic of the tumour. Vickers et al. (1965), however, felt that only the older parts of the tumour showed calcification; some of their illustrations showed no signs of calcification in large areas of the tumour. It is also possible that the ectopic site of the lesion in this case might in some way account for this absence of mineralization.

The position of the tumour in the lip is not so surprising as first appears. The enamel organs of the teeth are developed as bud-like swellings derived from oral epithelium. This epithelium then exerts an organizing effect upon the connective tissue cells of the dental pulp, transforming them into odontoblasts. These cells in turn produce the dentine. It is felt that this tumour might in a similar way arise from connective tissue cells of the lip which are changed into odontoblasts under the influence of the multipotential oral epithelium. The view that the oral epithelium is in fact multipotential is supported by the fact that numerous authors (Fish, 1948; Champion, Moule, and Wilkinson, 1951; Wilkinson, 1952; Stanley and Krogh, 1959) have reported ameloblastomas arising from oral mucosa remote from the teeth.

We wish to thank Professor P. O. Yates for helpful discussion, Mr. J. G. Edmunds for the preparation of the histological material, and Mrs. J. Cornwell for secretarial assistance.

\section{REFERENCES}

Champion, A. H. R., Moule, A. W., and Wilkinson, F. C. (1951). Brit. dent. J., 90, 143.

Chaudhry, A. P., Holte, N. O., and Vickers, R. A. (1962). Oral Surg., 15, 843.

Fish, E. W. (1948). Surgical Pathology of the Mouth, p. 430. Pitman, London.

Ivy, R. H. (1948). Oral Surg., 1, 1074.

Lucas, R. B. (1964). In Pathology of Tumours of the Oral Tissues. p. 62. Churchill, London.

Meyer, W. (1935). Meyer's Normal Histology and Histogenesis of the Human Teeth and Associated Parts. Translated and edited by H. R. Churchill, p. 87. Lippincott, Philadelphia.

Pindborg, J. J. (1958). Cancer (Philad.) 11, 838.

Stanley, H. R., Jr., and Krogh, H. W. (1959). Oral Surg., 12, 760. Stoopack, J. C. (1957). Ibid., 10, 807.

Thoma, K. H., and Goldman, H. M. (1946). Amer. J. Path., 22, 433. Vickers, R. A., Dahlin, D. C., and Gorlin, R. J. (1965). Oral Surg., 20, 476.

Wilkinson, F. C. (1952). Med. Press, 228, 90.

Wunderer, S. (1953). Os. Z. Stoma., 50, 567. 